\title{
Evaluation in a controlled environment of a low-cost IR sensor for indoor thermal comfort measurement
}

by G.M. Revel*, M. Arnesano*, F. Pietroni*, M. Schmidt** and O. Kaschtschejewa**

* Università Politecnica delle Marche, Department of Industrial Engineering and Mathematical Sciences, Ancona, Italy, m.arnesano@univpm.it

** Universität Stuttgart, Institut für GebäudeEnergetik, Stuttgart, Germany, olga.kaschtschejewa@ige.unistuttgart.de

\begin{abstract}
The present work illustrates the calibration and evaluation in a controlled environment of an innovative infrared measurement system developed for the real-time monitoring of indoor thermal comfort. The device is composed of an array of thermopiles and two fixed-step motors to be assembled and installed on the ceiling of the occupied room. The embedded tool performs the automatic scanning of each indoor surface to evaluate the temperature distribution. The mean radiant temperature $\left(T_{r}\right)$ and the predictive mean vote $(P M V)$ are computed for several positions in the environment and provided as output of the device through wireless connection.
\end{abstract}

\section{Introduction}

According to the rational approach of [1], the evaluation of thermal environments requires the knowledge of six quantities: two personal (clothing thermal insulation and metabolic rate) and four physical (air temperature, mean radiant temperature, air velocity and air humidity). These parameters need to be measured or estimated in order to derive the indoor thermal comfort by means of the PMV index [2]. As presented in [3], the mean radiant temperature $T_{r}$ is a very significant factor in moderate environments, especially in buildings whose envelopes are exposed to a strong solar radiation [4]. A method based on the computation of the angle factors [5] is capable estimate the $T_{r}$ with good accuracy, but it appears complex due to the need of measuring all the surface temperatures of the environment, ad-hoc equipment and the need of radiometers to measure the solar load in the presence of transparent surfaces. For example, in [6] a solution based on an infrared (IR) sensor is presented to derive the thermal comfort of a subject in a vehicle, where the mean radiant temperature is not measured following a standard procedure [3], but it is assumed equal to the local temperature measured. A similar application can be found also in the built environment, where IR sensors are used to derive the local temperature or to derive a global value of the mean radiant temperature with a sensor installed in a fixed location [7]. However, a cost-effective solution to apply the angle factors method and with the possibility to derive maps of mean radiant temperature is missing. The main issue is to achieve the right level of accuracy of the surface temperature measurement with low-cost IR sensors. For this reason, an ad-hoc solution is here described to provide $P M V$ index by means of continuous measurement of the indoor surfaces with an IR-based system and application of the angle factors methodology to calculate the $T_{r}$. The basics of the approach were presented by the authors in [8] with an initial validation to demonstrate its feasibility. The final system was presented with the description of the methodology applied and its validation process in [9] and [10] and is patent pending [11]. The present paper describes the evaluation and the calibration needed to employ low-cost IR sensors in the overall system. The calibration was performed in a controlled environment in order to assess the system performance and then to replicate the measurement methodology in real cases. The results of the IR sensor calibration are reported together with the analysis of the IR measurement impact in the overall process of calculating the comfort index.

\section{Applied methodology and system description}

The solution proposed in this paper is a low-cost tool (about 200€) for the real-time monitoring of indoor thermal comfort. The concept relies on an IR scanning system to install on the ceiling of the room, that measures the indoor surface temperatures, sends them to the control unit to calculate the mean radiant temperature $T_{r}$ and $P M V$ for several locations inside the room. The mean radiant temperature is derived for multiple positions of the subject inside the room according to the angle factors algorithm, as presented in the ISO 7726 [8]. The $T_{r}$ is computed from the weighted average of the internal surface temperatures $T_{i}$ and the respective view factor in relation to a subject, $F_{s-i}$, for $N$ surfaces:

$$
T_{r}^{4}=\sum_{i=1}^{N} F_{s \rightarrow i} T_{i}^{4}
$$


A mathematical expression developed by Cannistraro et al. [12] was used to calculate the view factors between a subject and internal surfaces. This approach, turned into an algorithm, automatically computes the coefficients differentiating the kind of surface considered (vertical or horizontal). The mean radiant temperatures, retrieved as described above, are then used to calculate the PMV index according to the Fanger's theory of the human thermal balance [1]. The $P M V$ is computed by the combination of environmental and personal parameters:

$$
P M V=f\left(T_{a}, T_{r}, V_{a}, R H, I_{c l}, M\right)
$$

where $T_{a}\left[{ }^{\circ} \mathrm{C}\right]$ is the air temperature, $T_{r}\left[{ }^{\circ} \mathrm{C}\right]$ is the mean radiant temperature, $V_{a}[\mathrm{~m} / \mathrm{s}]$ is the air velocity, $R H[\%]$ the relative humidity, $I_{c l}$ is the clothing thermal insulation (expressed in clo, where $1 \mathrm{clo}=0.155 \mathrm{~m}^{2} \mathrm{~K} / \mathrm{W}$ ) and $M$ is the metabolic rate (expressed in met, where 1 met $=58.2 \mathrm{~W} / \mathrm{m}^{2}$ ).

The whole procedure to configure, control and acquire data is managed by a control unit. It is composed of a commercial board (Arduino Mega) and all the electronics needed for sensors integration and wired/wireless communication (i.e. Bluetooth for interaction with Android devices through a dedicated GUI). The inputs required to perform the algorithms embedded can be stored directly into the microcontroller EEPROM memory, or updated by the user and/or the technician. Figure 1 illustrates all the steps performed by the microcontroller to achieve the continuous measurement of the thermal comfort by means of $P M V$ index.

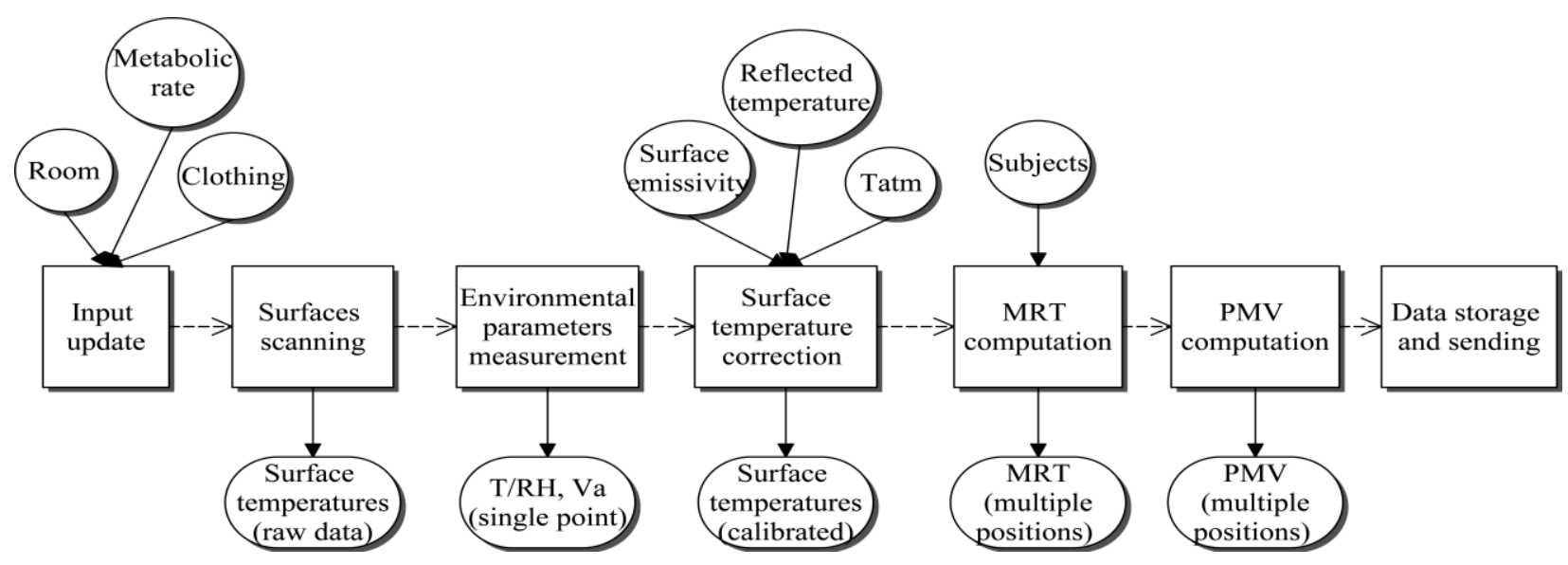

Fig. 1. On-board procedure for continuous thermal comfort monitoring

The user can interact with the system through the terminal with the user interface implemented (PC or Android device) and is asked to provide the inputs required for the calculation of thermal comfort index (room geometry, subject positions and their personal parameters, metabolic activity and clothing thermal insulation). The microcontroller performs the automatic scanning of all the surfaces of the room, provides the needed measurements through integrated sensors and formulas implemented into the embedded $\mathrm{C}++$ libraries and then sends the results back to the device for the realtime monitoring and post-processing.

Next paragraphs describe in details the components used to assembly the system and the methodology applied to address the specific measurement requirements of the solution proposed.

\subsection{Low-cost IR scanning system}

The core of the device consists of an array of thermopiles for non-contact IR temperature measurement and two servos to manage the orientation of the sensor $\left(0^{\circ}-180^{\circ}\right.$ in both directions), as presented in figure 2 . This device, installed on the ceiling of the room and possibly in the center, allows the continuous measurement of the indoor surface temperatures. Depending on the Field of View (FOV) of the sensor $\left(5.12^{\circ}\right.$ by $6^{\circ}$ for each pixels in the row), an embedded

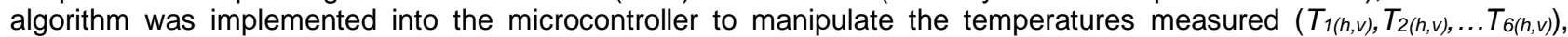
where $h$ and $v$ represents the horizontal and vertical orientation of the sensor during the acquisition. The application of this algorithm provides low-resolution thermal images as output for each surface. The IR sensor is a commercial solution (array of eight thermopiles arranged in a row, built in electronics and a silicon lens), which provides a temperature measurement of eight consecutive points with a resolution of $1^{\circ} \mathrm{C}$ each. A methodology to correct the surface temperature, based on its emissivity and environmental factors, is applied as part of the complete measurement process, as discussed above. 
a)

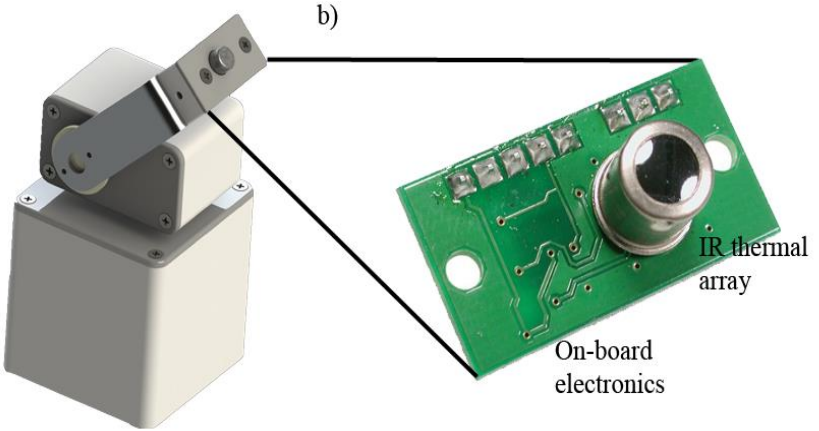

Fig. 2. IR scanning system. a) Assembled device (IR sensor + servos); b) Detail of the thermopile array adopted

The issue of correcting the infrared emissivity is addressed to reduce the measurement uncertainty. In fact, an on-board correction of the IR raw measurement is implemented by means of the following equation:

$$
T_{o b j}^{4}=\frac{1}{\varepsilon \tau} T_{t o t}^{4}-\frac{1-\varepsilon}{\varepsilon} T_{r e f l}^{4}-\frac{1-\tau}{\varepsilon \tau} T_{a t m}^{4}
$$

where $\varepsilon$ is the surface average emissivity, $\tau$ is the transmission coefficient of the atmosphere (assumed as a constant value of 0.99), $T_{\text {tot }}$ is the total temperature (raw value) measured by the IR sensor, $T_{\text {refl }}$ is the reflected temperature and $T_{\text {atm }}$ is the temperature of the atmosphere (equals to indoor air temperature). The average emissivity of the surface has to be provided as input of the algorithm, while the reflected temperature is computed directly by measuring the contribution of the opposite surface with an emissivity set to 1 . Given that the IR sensor is installed on the ceiling, its inclination angle could affect the accuracy of the measuring procedure. However, the maximum angle of incidence of the IR ray is generally equal to $25^{\circ}$ : according to the polar diagrams of the infrared emissivity of the material in consideration, as in figure 3 , the emissivity can be assumed as constant within certain limit values of the incidence angle. Looking at the graph, the emissivity of most nonmetallic and metallic materials does not change within the maximum inclination of the IR sensor [13]. In any case, this effect was considered and assessed during the calibration procedure presented in the next sections.

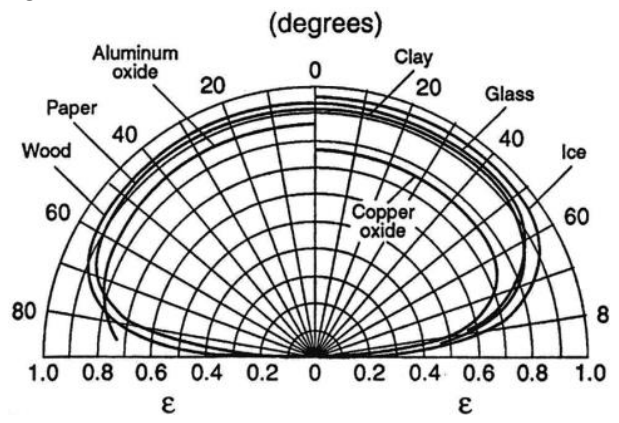

Fig. 3. Polar diagrams of the IR emissivity (image extracted from [13])

\subsection{Environmental sensors}

A low-cost integrated T/RH sensor allows the single-point measurement of the air temperature $\left(T_{a}\right)$ and relative humidity $(R H)$ parameters, which are required to calculate the $P M V$ index. It is based on DS18B20 1-Wire digital thermometer to measure the temperature and polymer humidity capacitor for $R H$ and they are both connected to an 8-bit single chip computer. The output is a calibrated digital signal that derives from a previous calibration and coefficients saved in the OTP memory. Table 1 summarizes the technical specification of the sensor.

Table 1. T/RH sensor specification. (*) This parameters derives from a calibration conducted in a climatic chamber of UNIVPM

\begin{tabular}{|c|c|c|}
\hline Parameter & Temperature & Humidity \\
\hline Measuring range & $-40 \div 125^{\circ} \mathrm{C}$ & $0 \div 100 \%$ \\
\hline Accuracy & $\pm 0.3^{\circ} \mathrm{C}^{(*)}$ & $\pm 2 \%$ \\
\hline Resolution & $\pm 0.1^{\circ} \mathrm{C}$ & $\pm 0.1 \%$ \\
\hline Repeatability & $\pm 0.2^{\circ} \mathrm{C}$ & $\pm 1 \%$ \\
\hline
\end{tabular}




\begin{tabular}{|c|c|c|}
\hline Hysteresis & - & $\pm 0.3 \%$ \\
\hline Long-term stability & - & $\pm 0.5 \% /$ year \\
\hline
\end{tabular}

A low-cost flow sensor (IST FS5), based on the thermal conductometric principle, has been adopted for singlepoint air velocity measurement. The sensor includes two platinum resistors in a chip and can be used as a constant temperature anemometer (CTA) through an electric circuit provided by the sensor manufacturer. An ad-hoc PCB was developed and integrated in the control unit to derive the air velocity, as a function of the bridge voltage measured by means of a 12-bit A/D Converter. The calibration curve has been found by means of a calibration conducted in the UNIVPM laboratory, with a reference anemometer (probe AP3203 of HD32.1 microclimate station), whose nominal accuracies are $\pm 0.02 \mathrm{~m} / \mathrm{s}$ and $\pm 0.1 \mathrm{~m} / \mathrm{s}$ in a range of $0.05 \div 1 \mathrm{~m} / \mathrm{s}$ and $1 \div 5 \mathrm{~m} / \mathrm{s}$ respectively. The sensor presents an accuracy of $\pm 0.06 \mathrm{~m} / \mathrm{s}$ in a range of $0 \div 2 \mathrm{~m} / \mathrm{s}$.

\section{IR system calibration}

The surface measurement performed by the IR scanning system was calibrated by an experiment conducted in a test chamber of Institute für Gebäude Energetik (IGE) in Stuttgart University. The site (figure 4 a)) is a room of $3.6 \times 4.2 \times 3.0 \mathrm{~m}$, with two black-painted walls that can be heated or cooled with hot and cold water supply system installed inside the walls. The air conditions were controlled with an air conditioner through ventilation channels connected with the test chamber. The environmental parameters can be set according to the ranges below:

- Indoor Air Temperature: $10 \div 50^{\circ} \mathrm{C}$;

- Indoor Relative Humidity: $40 \div 100 \%$;

- $\quad$ Surfaces Temperature: $10 \div 95^{\circ} \mathrm{C}$.

A 7-hour test was performed to provide the calibration of the IR system measurement and to estimate its accuracy. The system performed a scanning of the single surface and provided the low-resolution thermal image with a sample rate of one sample every 5 minutes. Four K-type thermocouples (with an accuracy of $\pm 0.6^{\circ} \mathrm{C}$ ) were mounted on the surface, as in figure $4 \mathrm{~b}$ ) to compare the results and derive the calibration parameters. The surface S1 was automatically heated and cooled within the test, covering a range of $15 \div 45{ }^{\circ} \mathrm{C}$ (figure $4 \mathrm{C}$ )).

a)

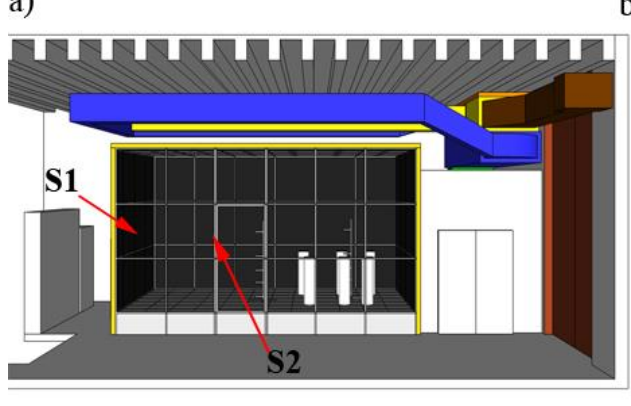

b)

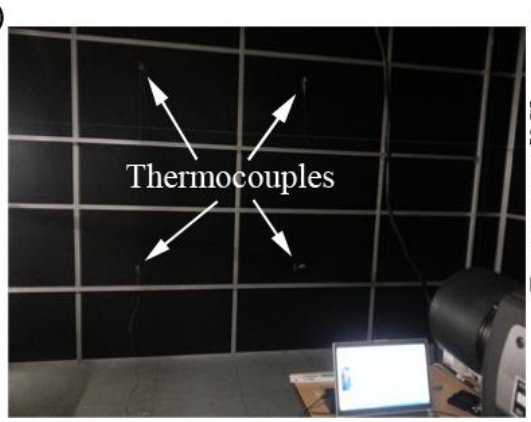

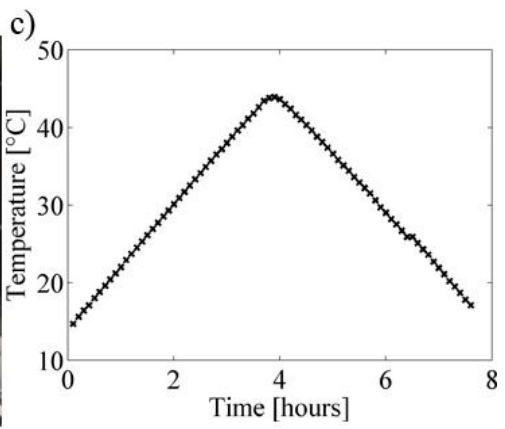

Fig. 4. Test chamber used for the calibration (a), details of surface $S 1$ with the thermocouples installed (b), average temperature profile of the surface S1 during the test (c)

A thermal camera (FLIR S40) was adopted to estimate the mean emissivity of the surface (black-painted aluminum), which turned out to be 0.89 . This value was assumed as constant during the complete scanning procedure, because of the low angle of incidence of the IR sensor (as discussed in the section 2.1, the maximum IR sensor inclination of $20^{\circ}$ was below the limit value for this assumption). The reflected ambient temperature was determined with a crumpled piece of aluminum foil fixed on the wall surface, in the field of view of the thermal image. Based on standards [14], the reflected ambient temperature is equal to the average temperature of the foil target, when the IR camera emissivity at this point is set to equal 1.0 as usually done for diagnostic purposes, i.e. in building envelopes, as in [15]. The atmospheric temperature was continuously measured during the test with a K-type thermocouple. The following figure shows an example of thermal images resulting from a single acquisition step from both thermal camera and IR system. 


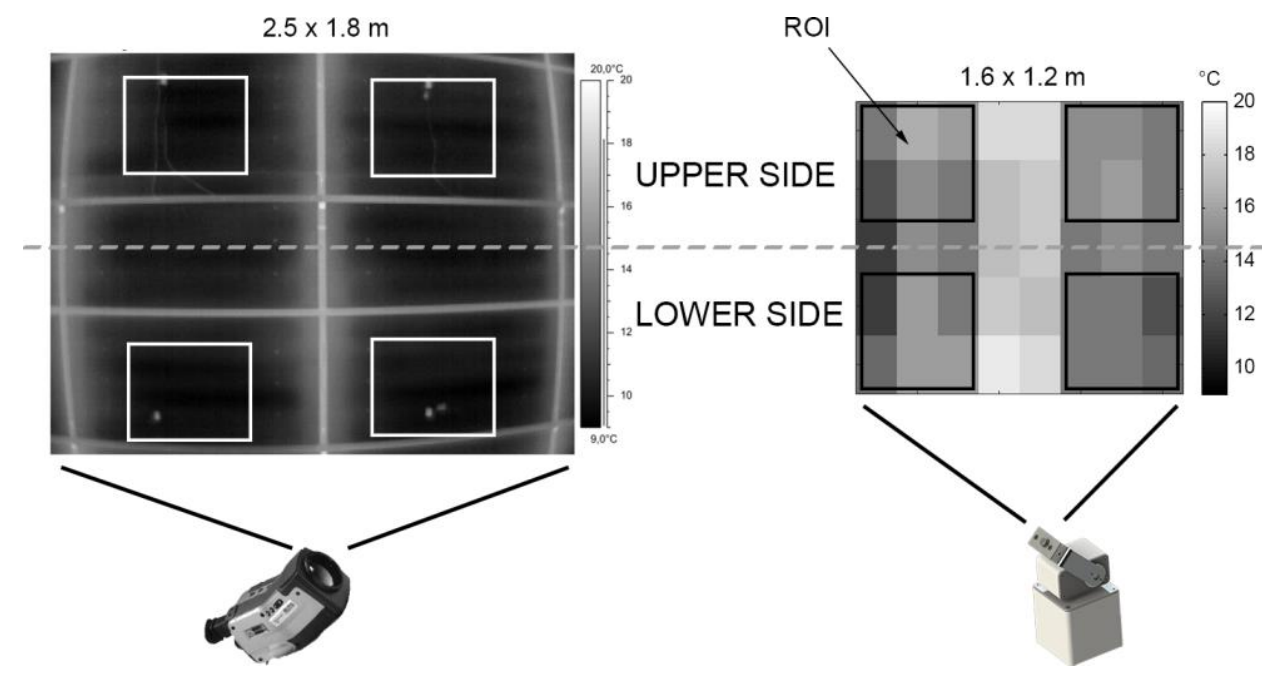

Fig. 5. Example of thermal image acquired with the thermal camera (left) and low-resolution image from the IR system (right). The white and black rectangles inside the thermal images represent the ROIs considered for the calibration procedure

Depending on the FOV of the IR sensor and its position within the test conducted, a matrix of $5 \times 8$ samples was provided as final output for each acquisition, where each point is the IR temperature measurement in an area of $20 \times 24$ $\mathrm{cm}$. The calibration was performed comparing the values measured by the thermocouples with the mean value of the ROIs (region of interest) for both the IR systems. In particular, 4 ROIs were identified, where the thermocouples were placed and the analysis was conducted for the average values of the ROIs in the upper and lower side and the mean value of all the ROIs. The regions of interest for the thermal camera were chosen manually with its analysis PC software ThermaCam Research post-processing the images acquired, and for the IR system matrices of $3 \times 2$ pixels were extracted, as represented in figure 5. The incidence angle of the IR sensor was in the range of $5^{\circ}$ to $10^{\circ}$ for the upper ROIs and $20^{\circ}$ to $25^{\circ}$ for the lower ROIs. In addition, the calibration was performed applying the mere correction curve (case 1 in table 2) and with the implementation of the Eq. (1) to compensate the emissivity (case 2).

Table 2. Results of the calibration procedure

\begin{tabular}{|c|c|c|c|c|c|c|c|c|c|}
\hline \multirow[b]{2}{*}{ Case } & \multicolumn{3}{|c|}{ Upper side } & \multicolumn{3}{|c|}{ Lower side } & \multicolumn{3}{|c|}{ Average values } \\
\hline & Sensitivity & $\begin{array}{l}\text { Offset } \\
{\left[{ }^{\circ} \mathrm{C}\right]}\end{array}$ & $\begin{array}{l}\text { STD } \\
{\left[{ }^{\circ} \mathrm{C}\right]}\end{array}$ & Sensitivity & $\begin{array}{l}\text { Offset } \\
{\left[{ }^{\circ} \mathrm{C}\right]}\end{array}$ & $\begin{array}{l}\text { STD } \\
{\left[{ }^{\circ} \mathrm{C}\right]}\end{array}$ & Sensitivity & $\begin{array}{l}\text { Offset } \\
{\left[{ }^{\circ} \mathrm{C}\right]}\end{array}$ & $\begin{array}{l}\text { STD } \\
{\left[{ }^{\circ} \mathrm{C}\right]}\end{array}$ \\
\hline Thermal camera & 1.1 & -0.9 & \pm 1.4 & 1.1 & -0.8 & \pm 1.3 & 1.1 & -0.8 & \pm 1.3 \\
\hline $\begin{array}{l}\text { IR system } \\
\text { (case 1) }\end{array}$ & 0.9 & 4.7 & \pm 0.9 & 0.9 & 5.9 & \pm 1.5 & 0.9 & 5.0 & \pm 0.9 \\
\hline $\begin{array}{l}\text { IR system } \\
\text { (case 2) }\end{array}$ & 1.0 & 3.9 & \pm 0.9 & 1.0 & 5.2 & \pm 1.5 & 1.0 & 4.2 & \pm 0.9 \\
\hline
\end{tabular}

The uncertainty of the IR system increases with the angle of incidence with the surface $\left( \pm 1.5^{\circ} \mathrm{C}\right.$ in the lower side respect to $\pm 0.9^{\circ} \mathrm{C}$ in the upper side), but it is reduced to $\pm 0.9^{\circ} \mathrm{C}$ performing the calibration with the average values of all the ROIs. The implementation of a methodology to correct on-board the IR measurement (case 2) resulted in an improvement of the calibration coefficient (slight improvement in the sensitivity and reduction in the offset), but the same accuracy levels were found.

\section{Analysis of results}

\subsection{Surface temperature measurement}

The performance of the IR system after the calibration procedure was evaluated at first comparing the surface temperature measurement with the same reference system (4 thermocouples), while the surface was heated/cooled and maintained to a constant temperature for about 1 hour. Three cases of steady temperature were analysed: $10^{\circ} \mathrm{C}, 50^{\circ} \mathrm{C}$ and $25^{\circ} \mathrm{C}$. The first two situations are slightly outside the calibration range (which was $15 \div 45^{\circ} \mathrm{C}$ ), while the third represents a temperature generally present in buildings (e.g. offices, classroom) walls not exposed to the exterior. The comparison between the average values of the ROIs of the IR matrix and the thermocouples are reported in table 3 by means of its residuals $M \pm \sigma S$, where $M$ is the mean value, $S$ the standard deviation and $\sigma$ the coverage factor $(\sigma=2)$. 
Table 3. Performance of the IR system measurement after calibration

\begin{tabular}{|c|c|c|c|}
\hline Set temperature $\left[{ }^{\circ} \mathrm{C}\right]$ & IR system (A) & IR system (B) & IR system (C) \\
\hline 10 & $5.1 \pm 0.5^{\circ} \mathrm{C}$ & $2.0 \pm 0.5^{\circ} \mathrm{C}$ & $0.9 \pm 0.5^{\circ} \mathrm{C}$ \\
\hline 50 & $4.5 \pm 0.6^{\circ} \mathrm{C}$ & $2.3 \pm 0.7^{\circ} \mathrm{C}$ & $0.3 \pm 0.6^{\circ} \mathrm{C}$ \\
\hline 25 & $4.2 \pm 0.4^{\circ} \mathrm{C}$ & $1.0 \pm 0.4^{\circ} \mathrm{C}$ & $0.0 \pm 0.4^{\circ} \mathrm{C}$ \\
\hline
\end{tabular}

According to these tests, a statistical difference $(p<0.05)$ between the average temperature measured by the thermocouples and the IR system occurred in all the cases, except for the situation within the calibration range $\left(25^{\circ} \mathrm{C}\right)$, after the application of the correction based on the emissivity compensation (case $\mathrm{C}$ ). This proves that the system is capable of providing IR measurements of the surfaces with the right level of accuracy in the range $15 \div 45^{\circ} \mathrm{C}$, while it tends to overestimate outside this range. However, it is important to notice how the residuals improves respect to the other cases: the average offset was greatly reduced for both the raw data (case A) and after the calibration of the IR system without the emissivity compensation methodology (case B).

\subsection{Thermal comfort}

The final performance of the system considering the thermal comfort was assessed with another test, where the attention was focused on the capability of monitoring the real-time mean radiant temperature $T_{r}$ and $P M V$. The IR system was validated in two different positions comparing the outputs of the system with the values provided by microclimate stations, placed inside the test room, as shown in figure 6 . The microclimate station represents the standard for shortterm monitoring of indoor thermal comfort and comprises a series of sensing probes to measure the environmental parameters (air temperature, relative humidity, air velocity, mean radiant temperature), which are all required to calculate the PMV index with data post-processing. In particular, $T_{r}$ is calculated by means of the combination of the air temperature $\left(T_{a}\right)$, air velocity $\left(V_{a}\right)$ and the temperature measured with a black-globe thermometer probe $\left(T_{g}\right)$.
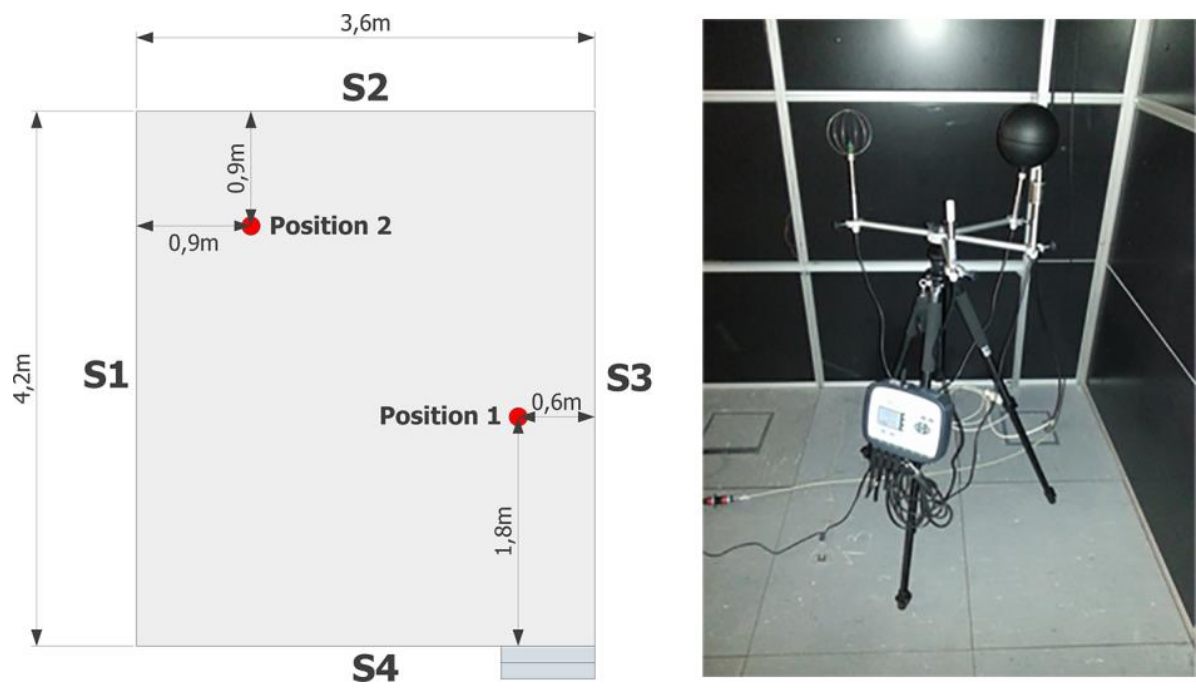

Fig. 6. Position of the microclimate stations during the test conducted (left), HD32.1 microclimate station (right)

Table 4. Microclimate stations accuracies

\begin{tabular}{|c|c|c|c|c|}
\hline \multirow{2}{*}{ Parameter } & Microclimate station (Position 1) & \multicolumn{2}{|c|}{ Microclimate station (Position 2) } \\
\cline { 2 - 5 } & Sensor & Accuracy & Sensor & Accuracy \\
\hline Air temperature $\left[{ }^{\circ} \mathrm{C}\right]$ & PT100 & $\pm 0.2^{\circ} \mathrm{C}$ & PT100 & $\pm 0.1^{\circ} \mathrm{C}$ \\
\hline Relative humidity $[\%]$ & Humidity probe & $\pm 2 \%$ & Capacitive sensor & $\pm 2.5 \%$ \\
\hline Air velocity $[\mathrm{m} / \mathrm{s}]$ & Anemometer & $\begin{array}{c} \pm \%(<1 \mathrm{~m} / \mathrm{s}) \\
\pm 1.5 \% \text { otherwise }\end{array}$ & Anemometer & $\begin{array}{c} \pm 0.02 \mathrm{~m} / \mathrm{s}(<1 \mathrm{~m} / \mathrm{s}) \\
\pm 0.1 \mathrm{~m} / \mathrm{s} \text { otherwise }\end{array}$ \\
\hline Mean radiant temperature $\left[{ }^{\circ} \mathrm{C}\right]$ & Thermocouples & $\pm 0.6^{\circ} \mathrm{C}$ & Black globe & $\pm 0.1^{\circ} \mathrm{C}$ \\
\hline
\end{tabular}

The microclimate station placed in position 1 was not equipped with the black globe thermometer. For that position the mean radiant temperature was computed applying the angle factor methodology proposed by ISO 7726 , using the surface temperatures measured with the thermocouples (4 for each surface). 
The surfaces S1 and S2 were heated and cooled following predefined profiles in order to simulate a real case situation, for example the solar radiation that heats a wall exposed to the exterior. The IR system data were analysed and processed in order to provide $T_{r}$ and $P M V$ of the two positions where the microclimate stations were placed. All the microclimate station probes were placed at the height of $1.1 \mathrm{~m}$, which represents the "standing position" of the subject to compute the $T_{r}$. The sampling frequency for the data logging was set to one sample each 10 minutes, which is the time required for the IR system to perform all the steps and embedded calculations, as in figure 1 . The IR system automatically measures all the indoor surfaces, except for the ceiling, which value was assumed equal to the temperature of the integrated thermistor of the IR sensor (placed in the middle of the ceiling). Data were processed to derive $T_{r}$ and $P M V$ for the positions where the microclimate stations were placed. The analysis was conducted for the raw IR measurement of the sensor (without the calibration) and after the calibration procedure, with/without the emissivity compensation based on Eq. (1). The table 5 reports the results of the test and figure 7 shows an example of surface temperatures acquisition within the test conducted. In both the examples, it is clear that the system raw measurements (case A) present high deviations respect to the reference and need to be corrected. The application of the calibration, without taking into consideration the surface emissivity (case B), improves the temperature measurement but tends to overestimate. The complete calibration based on emissivity compensation (case $\mathrm{C}$ ) provides an accurate measurement of indoor surfaces and this result is in agreement with the previous tests.

Table 5. Validation of IR system for PMV measurement. Data comparison with reference sensors (thermocouples)

\begin{tabular}{|c|c|c|c|c|c|c|}
\hline \multirow{2}{*}{ Parameter } & \multicolumn{2}{|c|}{ IR system (A) } & \multicolumn{2}{|c|}{ IR system (B) } & \multicolumn{2}{c|}{ IR system (C) } \\
\cline { 2 - 6 } & Mean [ $\left.{ }^{\circ} \mathrm{C}\right]$ & STD [ $\left.{ }^{\circ} \mathrm{C}\right]$ & Mean $\left[{ }^{\circ} \mathrm{C}\right]$ & STD [ ${ }^{\circ}$ C] & Mean [ $\left.{ }^{\circ} \mathrm{C}\right]$ & $\mathrm{STD}\left[{ }^{\circ} \mathrm{C}\right]$ \\
\hline$T$ (front surface) (S1) & 3.1 & \pm 1.7 & 1.0 & \pm 0.7 & -0.1 & \pm 0.8 \\
\hline$T$ (rear surface) & 3.9 & \pm 0.3 & 1.4 & \pm 0.5 & 0.3 & \pm 0.4 \\
\hline$T$ (left surface) & 3.3 & \pm 0.6 & 0.8 & \pm 0.9 & -0.1 & \pm 0.9 \\
\hline$T$ (right surface) (S2) & 3.8 & \pm 1.9 & 1.3 & \pm 1.7 & 0.1 & \pm 1.8 \\
\hline$T$ (floor) & 3.6 & \pm 0.9 & 1.0 & \pm 0.7 & 0.1 & \pm 0.6 \\
\hline$T$ (ceiling) & -0.5 & \pm 0.4 & -0.5 & \pm 0.4 & -0.5 & \pm 0.4 \\
\hline
\end{tabular}
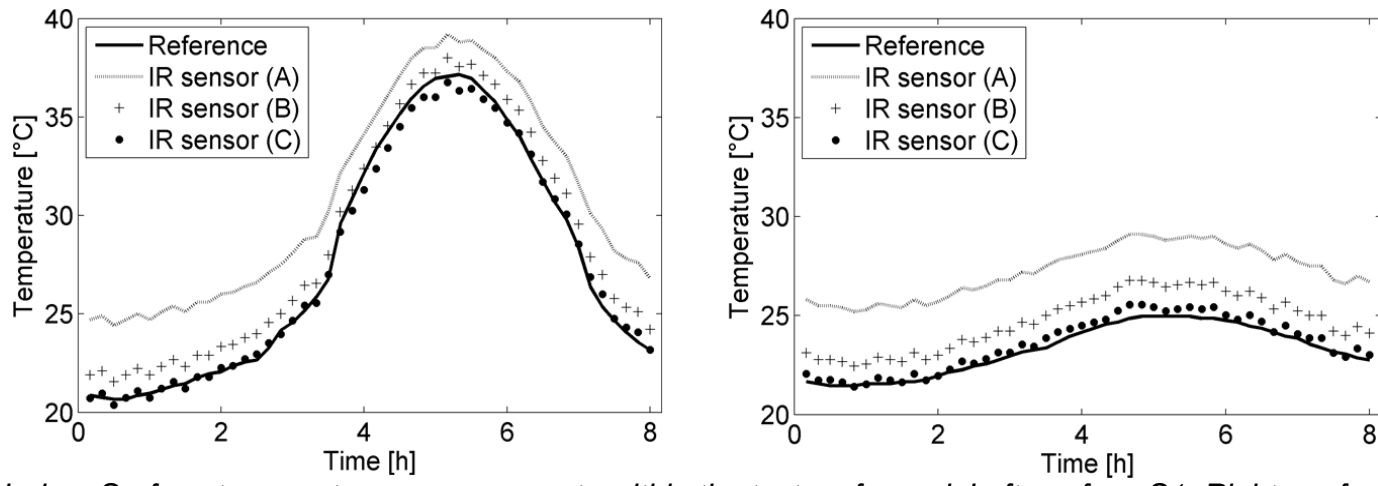

Figure 7. Indoor Surface temperature measurements within the test performed. Left: surface S1. Right: surface S3

An analysis based on statistical inference proves that the compensation of IR measurement by taking into account the surface emissivity, reflected and atmospheric temperature is essential to provide an accurate measurement of indoor walls. A t-test was adopted to check if a statistical difference $(p<0.05)$ exists between the residuals (thermocouples $-I R$ sensor data), with the hypothesis of Gaussian distribution with mean 0 and deviation 1 . This test can find a graphical representation by means of the $\mathrm{Cl}$ (confidence interval) for the variable chosen. Figure 8 shows the $\mathrm{Cl}$ for all the indoor surfaces, which are directly measured with the solution adopted.

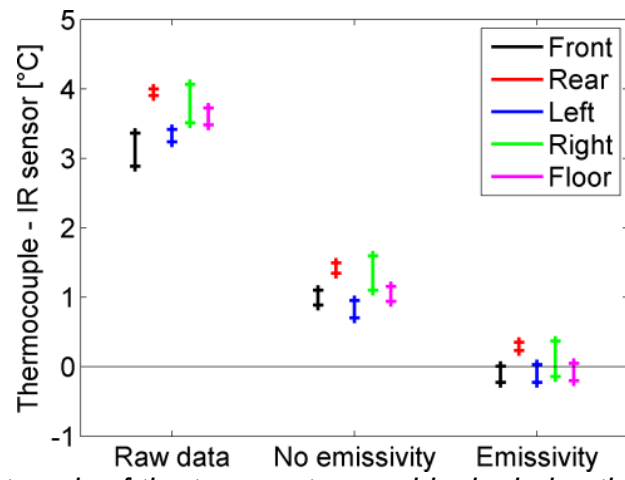

Figure 8. Confidence intervals of the temperature residuals during the test conducted 
The results show that only the calibration of the IR system, based on the emissivity compensation, is able to provide a correction of the measurement, which does not present a statistical difference $(p<0.05)$ with the reference system. A slight offset occurs only for the rear wall, but it is negligible since it is lower than the system accuracy. The application of the complete calibration leads to an improvement in all the single surface measurement, with an improvement also in the $T_{r}$ and $P M V$ (no statistical difference, at $p<0.05$, is found between the microclimate stations and the IR system and limited deviation respect to microclimate stations, as shown in figures 9 for the position 2). The final deviations are respectively:

- $\quad 0.1 \pm 0.4^{\circ} \mathrm{C}$ for $T_{r}$ (position1)

- $\quad 0.0 \pm 0.1$ for $P M V$ (position1)

- $\quad 0.0 \pm 0.5^{\circ} \mathrm{C}$ for $T_{r}$ (position2)

- $\quad 0.0 \pm 0.2$ for $P M V$ (position2)
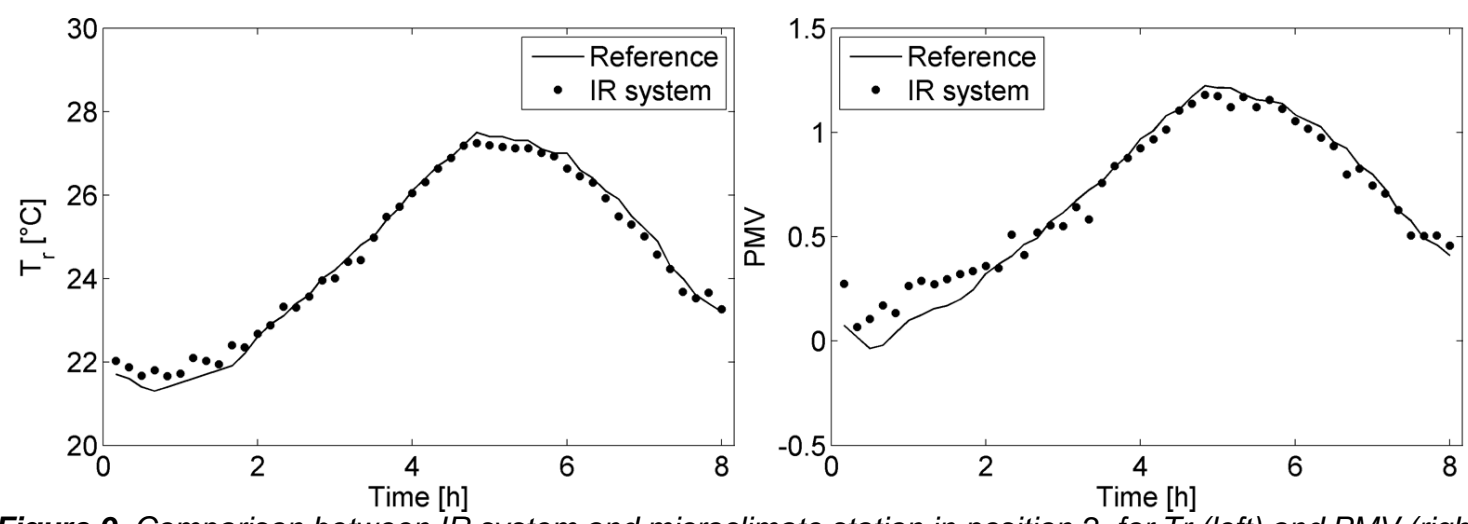

Figure 9. Comparison between IR system and microclimate station in position 2, for Tr (left) and PMV (right)

\section{Conclusion}

The results show that the proposed system is able to provide real-time measurement of the surface temperature with an accuracy comparable to a thermal camera. The system is capable of providing spatial information of the surface with a very-low resolution image, but this is acceptable for the aim of the system, which is the real-time measurement of indoor thermal comfort. The application of the methodology proposed by GUM [16] for the uncertainty estimation of PMV index showed that the system proposed is capable of providing an estimation of the thermal comfort with \pm 0.2 discrepancy respect to commercial solutions (microclimate station), with the possibility of a real-time and spatial measurement. This result can be achieved only after a dedicated calibration of the IR sensor for the typical indoor built environment as presented in this study.

\section{Acknowledgments}

This work is co-founded by the European Commission within the FP7 European Project CETIEB (Cost Effective Tools for Better Indoor Environment in Retrofitted Energy Efficient Buildings), Grant agreement no: 285623.

\section{REFERENCES}

[1] Fanger P.O., "Thermal comfort". Danish Technical Press, Copenhagen, 1970.

[2] ISO, "7730. 2005. Ergonomics of the thermal environment - Analytical determination and interpretation of thermal comfort using calculation of the PMV and PPD indices and local thermal comfort criteria". International Standardization Organization, Geneva, 2005.

[3] Alfano F., Dell'Isola M., Palella B., Riccio G., Russi A., "On the measurement of the mean radiant temperature and its influence on the indoor thermal environment assessment". Building and Environment, vol. 63, pp. 79-88, 2013.

[4] Atmaca I., Kaynakli O., Ygit A., "Effects of radiant temperature on thermal comfort". Building and Environment, vol. 42, pp.3210-20, 2007.

[5] ISO," 7726. 2002. Ergonomics of the thermal environment - instruments for measuring physical quantities". International Standardization Organization, Geneva, 2002.

[6] Mola S., Malvicino C., "System for controlling an air-conditioning system within an environment, in particular passenger compartment of a vehicle". US00793 1209B2, 2011.

[7] Hruska F. "Project of thermal comfort system"”. International Journal of Mechanics, vol. 5, pp. 284-293, 2011.

[8] Revel G.M., Sabbatini E., Arnesano M., "Development and experimental evaluation of a thermography measurement system for real-time monitoring of comfort and heat rate exchange in the built environment". Measurement Science and Technology, vol. 23(035005), 2012. 
[9] Revel G.M., Arnesano M., Pietroni F., "An Innovative Low Cost IR System for Real-Time Measurement of Human Thermal Comfort”. Proceedings of IAQ2013 conference, Vancouver (Canada), 2013.

[10] Revel G.M., Arnesano M., Pietroni F., "A low-cost sensor for real-time monitoring of indoor thermal comfort for ambient assisted living". Ambient Assisted Living - Italian Forum 2013, (Switzerland: Springer International Publishing).

[11] Revel G.M., Arnesano M., Pietroni F., "Sistema e metodo per il monitoraggio del comfort termico". MO2013A000279, 2013.

[12] Cannistraro G., Franzitta G., Giaconia C., Rizzo G., "Algorithms for the calculation of the view factors between human body and rectangular surfaces in parallelepiped environments". Energy and Buildings 19(1) 51-6, 1992

[13] Maldague X.P.V., "Theory and Practice of Infrared Technology for Nondestructive Testing". Wiley-Interscience. 0471181900. 2001

[14] ASTM E1862 - 97(2002). "Standard test methods for measuring and compensating for reflected temperature using infrared imaging radiometers"

[15] Fokaides P.A., Kalogirou S.A., "Application of infrared thermography for the determination of the overall heat transfer coefficient (U-Value) in building envelopes". Applied Energy. doi:10.1016/j.apenergy.2011.05.014

[16] "Guide to the Expression of Uncertainty in Measurement" (Geneva: International Organization for Standardization) 1993 